\title{
Economic and Behavioral Assessment of Motivation Factors of Lebanese Monetary Donors to Non-Government Organizations (NGOs)
}

\author{
Bassam Charif Hamdar ${ }^{1, ~ *, ~ J e s s i c a ~ A n t o n i o s ~ L e ~ P o r ², ~ B a s i m a ~ D a n a ², ~ J i n a n e ~ M n e i m n e h ² ~}$ \\ ${ }^{1}$ Department of Economics, American University of Science and Technology, Beirut, Lebanon \\ ${ }^{2}$ Department of Marketing, American University of Science and Technology, Beirut, Lebanon
}

Email address:

bhamdar@aust.edu.lb(B. C. Hamdar)

${ }^{*}$ Corresponding author

\section{To cite this article:}

Bassam Charif Hamdar, Jessica Antonios Le Port, Basima Dana, Jinane Mneimneh. Economic and Behavioral Assessment of Motivation Factors of Lebanese Monetary Donors to Non-Government Organizations (NGOs). International Journal of Economic Behavior and Organization. Vol. 6, No. 1, 2018, pp. 11-21. doi: 10.11648/j.ijebo.20180601.12

Received: February 28, 2018; Accepted: March 14, 2018; Published: April 9, 2018

\begin{abstract}
In recent years, non-profit organizations proved to play a vital role in the community especially in a small country like Lebanon where goods and services to the population are very limited and only few alternatives are obtainable. Private individual charitable giving has gained much importance as a source of support for non-profit organizations. The aim of this paper is to assist these charitable organizations to better understand the motivating factors of Lebanese donors. This paper conducted a research on the effect of the gender and educational level of donors on their donation decisions, to know what motivates them to give to charity, what hinders them from giving more, and what affects their choice of the recipient NonGovernment Organizations (NGOs). Data from 235 respondents in Beirut, the authors were able to deduce three potential motivating factors affecting the donor; religion, human sympathy, and social solidarity, and three potential de-motivating factors (or barriers); non-transparency, lack of post donation reports, and the insistence in the request of donations. Moreover, three potential factors affecting the decision of donors to choose the recipient NGOs: Good reputation, same religious affiliation, and importance of the cases requesting donations. The results of this study will provide valuable insights into how donors engage with these non-profit organizations as well as pave the way for the NGOs to effectively influence the decisions and intentions of donors.
\end{abstract}

Keywords: Economic and Behavioral Assessment, Charitable Giving, Donors, Philanthropy, Motivation

\section{Introduction}

During the past few years, Lebanon has been a country of a great need to charitable giving due to the Syrian refugees' crisis and due to the bad economic condition of many Lebanese, and consequently Lebanon witnessed an increasing philanthropy activity in parallel with the birth of many non-profit organizations working in the charity domain trying to meet the social needs. This situation led to a rise in the fundraising activity among various charity institutions putting the donor under financial and social responsibility pressure, from one side, and putting the Non-Government organizations( NGOs) under the pressure of acquiring donors and motivating them to donate more, from the other side.
Donation from individual donors is important in philanthropy and a large amount of money is given by individual donors to philanthropy activities. However, with little and almost no research conducted in Lebanon about this issue, which is of a great importance, no clear donor motivation practices are adopted by the NGOs in Lebanon that conform to the donors' behavior towards the act of donating. In an increasingly donor-centered country, where donors are motivated to give by a variety of factors, and are able to choose from a growing number of organizations to support, researches that analyze differences among donor preferences, motivations, and priorities are urgently needed.

This paper sets out to better understand charitable giving by exploring the motivation factors of Lebanese individual 
monetary donors to non-profit organizations. In general, it tries to distinguish characteristics of donors to assist organizations in framing rational decisions on fundraising strategies and appropriate fundraising messages. More specifically, the focus is centered on whether differences in giving exist due to gender and education level. As women are becoming more present in the labor market, they are playing important role in philanthropy. Also, millennials, who are likely to have higher level of education than their previous generation $\mathrm{X}$, form an important sector of donors nowadays. Hence, gender and education level play an important role in influencing the donor behavior. In this paper, the authors will try to answer the following questions:

1) What are the top donors' motivation factors to donate and do they vary by the gender and educational level of the donors?

2) What are the top donors' de-motivation factors to donate and do they vary by the gender and educational level of the donors?

3) What are the top donors' motivation factors in choosing the $\mathrm{NGO}$, and do they vary by the gender and educational level of the donors?

\section{Literature Review}

\subsection{Charitable Giving Around the World, Motivations and Barriers}

The academic literature on charitable giving is enormous. On Google Scholar, the keyword 'charitable giving' yields more than 368,000 results. Charitable is best defined as "the voluntary donation of money to an organization benefiting others beyond one's own family". (Bekkers \& Wiepking, 2012).

Charitable donations form a substantial portion of income for many non-profit organizations across the world (Anheier \& Salamon, 2006). In the World Giving Index report of 2017, issued by the Charities Aid Foundation (CAF), from a data collected during 2016 from 139 countries that represent 5.2 billion adults, or $95 \%$ of the world's adult population, the results show that the top 10 countries by participation in donating money, among 139 countries, were consecutively: Myanmar, Indonesia, Malta, Iceland, Thailand, New Zealand, Netherlands, United Kingdom, Australia, Canada. However, Lebanon was ranked in 76th place among 139 countries around the world, with a score of $31 \%$ as World Giving Index, lower than the global average score of $33.3 \%$ (Charities Aid Foundation, 2017). The findings of that report show that "across fast developing countries the potential for giving is on the rise" and "it confounds traditional views of the link between wealth and generosity", confirming what is known: that giving is about spirit and inner motivation, not about financial means. (Charities Aid Foundation, 2017).

In an analysis of the above mentioned report, the economic research department of Byblos Bank-Lebanon stated in its publication "Lebanon this week", issued in November 2017 (Byblos Bank, 2017) that Lebanon was ranked in the "seventh place among 13 Arab countries. Lebanon also came in 17th place among 35 Upper Middle-Income Countries (UMICs) included in the survey." Also (Byblos Bank, 2017) indicated that "globally, charitable contributions in Lebanon are higher than in the Republic of Congo, Pakistan and Senegal, but lower than in South Sudan, Jordan and Brazil. Lebanon was also more benevolent than Romania, Argentina and Kazakhstan, but less giving than Turkmenistan, Jordan and Brazil among UMICs. Further, it was more philanthropic than Tunisia, Egypt, Palestine, Mauritania, Morocco and Yemen among Arab countries", and that "Lebanon received a score of $31 \%$, unchanged from the 2016 survey. Lebanon's score was lower than the global average score of $33.3 \%$, but higher than the UMIC's average score of $30.3 \%$ and the Arab average score of $30.2 \%$. Also, it was lower than the Gulf Cooperation Council (GCC) countries' average score of $43 \%$, but higher than that of non-GCC Arab countries of 26.3\%".

Therefore, it is very important to know who gives to charity, the causes, and why. The answers to these questions are of great practical importance for nonprofit organizations that rely on fundraising to generate income. A better understanding of donors' rationalities and their motivations to give is necessary for fundraising practitioners in NGOs, in order to know which characteristics of individuals influence donations and consequently to avoid making wrong assumptions about the motivation behind the giving decisions. Many previous researches tackled these issues from different perspectives in order to study the behavior of prospective donors to charity.

\subsection{Common Motivations of Donors to Give to Charity}

(Bekkers \& Wiepking, 2010) categorized and described the eight major mechanisms that drive charitable giving, addressing the question 'Why do people give?' The mechanisms are (1) awareness of need; (2) solicitation; (3) costs and benefits; (4) altruism; (5) reputation; (6) psychological benefits; (7) values; (8) efficacy.

In a survey conducted by The center of Philanthropy at Indiana University (2008), the five top motivations for charitable giving of donors were consecutively: "Providing for the basic needs of the very poor, desire to make the community a better place to live, giving the poor a way to help themselves, desire to make the world a better place to live, those with more have a responsibility to help those with less."

In a research report issued by Redbird on Canadian people, Murphy, L. (2001), "The most frequently reported motivations for making donations were feeling compassion for those in need $(90 \%)$, wanting to help a cause in which the donor personally believes $(86 \%)$, and wanting to make a contribution to the community $(80 \%)$. Donors also give when they have been personally affected by the cause of the organization $(62 \%)$.

In another research conducted by (The Canadian Centre for Philanthropy, 2004) which surveyed 14,724 Canadians aged 15 and older, $94 \%$ of donors cited that their motivation for donating was a sense of compassion for those in need, 
$91 \%$ stated that their motivation was a belief in the cause of the organization supported. $69 \%$ said that they were motivated to give because they or someone they knew were personally affected by the cause of the organization and $58 \%$ because they thought they owed something to their community. Nearly one third of donors (31\%) said that they donated to fulfill religious obligations or beliefs, and few donors $(13 \%)$ said that they were motivated by the tax credits offered by government in return for donating (The Canadian Centre for Philanthropy, 2004).

In Lebanon, the motivations for charitable giving are often driven by politics. Many political groups in Lebanon are associated with a specific religion; therefore, most philanthropy in Lebanon is sectarian in nature. Many of the major political and religious groups in Lebanon form their own philanthropic organizations to solicit donations from constituents and to gain loyalty by dispersing goods and services to their followers. For example, during elections, many political parties increase local giving to 'buy' or encourage votes and increase turnout

(Sharaiha \& Ibrahim, 2009).

Previous research shows that $71 \%$ of Lebanese people donated money or made other contributions to charity at an average of US\$136 per year, with more than one-third of citizens donating less than US\$50. With an estimated individual annual income of US\$8,336., this average constitutes $2 \%$ of personal income (Abouassi, 2006).

Also, In Lebanon, it is common to see people donating to charities out of a religious duty or social obligation (sadaqa or charity, zakat or alms, waqf or mortmain, etc ...), this donation may be monetary on in-kind donation, and occurs more often during the religious seasons. This explains why religion-based organizations receive most of the donations, and this also raises the question about the non-religious motivations of donors versus the religious obligations. (Abouassi, 2015)

\subsection{Gender Difference in Charitable Giving}

"Gender matters in philanthropy" (Mesch, Brown, Moore \& Hayat, 2011). And since gender is one of the most consistent demographic predictors of charitable giving; the effect of a donor's gender on charitable giving is receiving increasing attention in research.

Past research on gender differences in charitable giving finds that women are more likely to donate money and volunteer time to charitable organizations than men (Willer, Wimer \& Owens, 2015). In a global overview of the donation participation by gender around the world, the CAF World Giving Index (2017) recorded a slight difference between genders in money donations where men were $0.4 \%$ more likely than women to donate money. "Some countries do see more women donating than men, with the top 5, in order: Denmark, Sweden, New Zealand, Norway and Australia. In each case, women give significantly more than men. The Scandinavian countries in particular are known for high levels of gender equality. Efforts to improve gender equality across the globe are therefore likely to increase the proportion of women donating money" (Charities Aid Foundation, 2017)

\subsection{Motivations}

Men and women donate due to different motivations and differ in their preferences for different causes. For example, studies find that women are more likely to give to education related causes and health care organizations (Willer, Wimer \& Owens, 2015). By contrast, men's charitable giving has a very different complexion, with men giving at higher levels to sports, adult recreation, veterans, and civil rights organizations (Einolf 2011).

Past research on gender and prosocial emotions hypothesize that empathy can help explain the gender gap in charitable giving. "It has long been thought that altruism, which generally refers to prosocial behavior involving some cost to the self, is a trait more highly developed in women than in men" (Mills et al. 1989).

In a research conducted by (the Canadian Centre for Philanthropy, 2004), 74\% of women (vs. 63\% of men) said they donate because they or someone they knew had been affected by the cause of the organization. Women were also more likely than men to say that they donated because they felt they owed something to their community. On the other hand, women were somewhat less likely than men to say that they were motivated by government tax credits $(11 \%$ of women donors vs. $15 \%$ of male donors). This may be at least in part because men tend to earn more than women, which makes tax credits more valuable to men (The Canadian Centre for Philanthropy, 2004).

Some studies show that "women respond to emotional appeals more intensely and more frequently than men" (Mesch, Brown, Moore \& Hayat, 2011). The results of these studies indicated that the gender differences in motivations are as follows: "women score significantly higher than men on empathic concern and principle of care, these motives are positively and significantly related to giving for both men and women; women, more than men, are more likely to give and give more" (Mesch, Brown, Moore \& Hayat, 2011).

In a research that investigated donating behavior in Austria, it was noted that females were more likely to contribute to environmental issues and animal protection, whereas males more often supported local friendly societies. Another finding was about the forms of giving where women were noted to tend more often towards buying charity products and to donate goods such as clothes or furniture, whereas men preferred to donate blood and to carry out volunteer work in charitable organizations. However, gender was found to have no significant impact on amount donated and frequency of charitable giving. (Srnka, Grohs, \& Eckler, 2003).

A survey data analysis from the Midlife in the United States (MIDUS) survey, (Einolf, 2011) shows that women have stronger prosocial values. This could be a convincing explanation for differences in giving because prosocial values are good predictors of charitable giving. Persons who describe themselves as caring and empathic are more likely 
to report making donations to charitable causes (Einolf, 2009).

In a study at The Center on Philanthropy at Indiana University, (Kou, Han, \& and Frederick, 2009) found that the motivations for both genders to give, not including the religious belief, were as follows: feeling that those with more should help those with less $(62.7 \%$ of men and $74 \%$ of women) the fact that a charity helped the donor, donor's friends or family ( $48.3 \%$ of men and $57.6 \%$ of women) belief that charity can activate change or bring about a desired impact $(44.8 \%$ of men and $54.7 \%$ of women) help meet people's material needs ( $42.4 \%$ of men and $54 \%$ of women)".

\subsection{Education Level Differences in Charitable Giving}

"Positive relations between the level of education and giving are found in most empirical studies that have included education as a variable" (Wiepking \& Bekkers, 2011). In a research that investigated donating behavior in Austria "higher education was found to lead to significantly greater support for environmental and animal protection, for development aid and also for human rights organizations. People with lower education, on the other hand, tended to give significantly more often to health care organizations and emergency aid. Higher education also led to a significantly greater chance of being a member of a charitable organization paying a regular membership fee and of assuming (financial) responsibility for a person or a project; whereas lower education resulted in a significantly higher probability of giving at street collections and blood donations. Further, education was found to positively influence the amount donated, but did not show a significant impact on frequency of giving" (Srnka, Grohs, \& Eckler, 2003).

It is also interesting to note that, "among all donors, higher education is strongly associated with having a charitable bequest" (Kou, Han, \& Frederick, 2009).

\section{Donor's Decision Making Factors in Choosing the Recipient NGO}

Many researches about charitable giving focused on questioning how, how much, why, and what donors give, but little research is found questioning about how donors decide which charities to support and what factors affect their preferences. "In fact, donors create mental classifications of the types of charities that they will and will not countenance supporting" (Breeze, 2010)

In a research conducted in 2008 on donors who live in Thurston County, Washington (Adams and Cain, 2008), four factors affecting the donors' decision-making in choosing the recipient organization were recorded. These factors are: religious identity, effectiveness, being prior beneficiaries of the organization, and altruism. They found that "highly religious donors are more likely to give through religious organizations, and rank basic service organizations as more important than organizations that provide services such as environmental advocacy or cultural activities." As to organizational effectiveness, they found that higher levels of giving are correlated with higher effectiveness and that "donors are more likely to ask exactly where their donation will be used, how it will be applied, and whether in their own estimation that donation is doing anything to assist their chosen cause." As to prior beneficiaries they found that "donors who have previously benefited from philanthropic organizations are more likely to feel an obligation to give back to the community". "A person who was at one point in their life a beneficiary of a philanthropic organization may be more likely to give back to that organization or to a similar cause". The fourth factor affecting the donor's decision making in choosing the NGO is altruism: since non-profit organizations fall into several sectors, including public society benefit organizations, health and human services, arts, culture and humanities, environment and animals, international affairs, religious organizations, education, and others, many donors choose to support the NGO that assists people in need, out of pure altruistic factor (3.79 for male, 3.93 for females). (Adams and Cain 2008)

In a study on how donors in the UK go about making decisions regarding the destination of their charitable giving, the findings indicate that, "despite continuing widespread assumptions that need is the primary driver of charitable donations, giving decisions are also based on at least four other factors: donors' taste, personal background, concerns about charity competence and a desire for personal impact. In summary, people do not give to the most urgent needs, but rather they give to things that mean something to them". (Breeze, 2010)

\section{Research Methodology}

This research was designed to test theories of motivation as found in international literature by relating these findings to donors who live in Beirut, Lebanon. Google forms were used to distribute two electronic survey questionnaires, one in Arabic and the second in English, requesting demographic information as well as questions to assess motives and opinions of respondents. 235 responses were received, but the findings cannot be generalized to the entire country due to the homogeneity and size of the sample.

A combination of qualitative and quantitative data was used, to improve the evaluation by ensuring that the limitations of one type of data are balanced by the strengths of another.

\section{Results and Discussion}

This section analyzes the potential donors' motivation factors to donate and their relationship to gender, and education level.

\subsection{The Potential Motivations to Donating / in General}

The top motivating factor (figure 1) came out to be Religion/faith, it accounted for the largest share of donations 
being $56 \%$ of those who donate. The second motive came out to be human sympathy / emotion that triggered $28 \%$ of the donors. Although morality is always mediated by cultural discourses and shaped by structural factors, it also has a universalizing character because people have fellow feelings, shared human conditions, and has reason to value. The third motive came out to be the concept of social solidarity, being $14 \%$ out of those who donated.

These findings conform with (Sharaiha \& Ibrahim, 2009), as it was stated that most philanthropy in Lebanon is sectarian in nature, and with (Abouassi, 2015) as it was indicated that in Lebanon, it is common to see people donating to charities out of a religious duty or social obligation

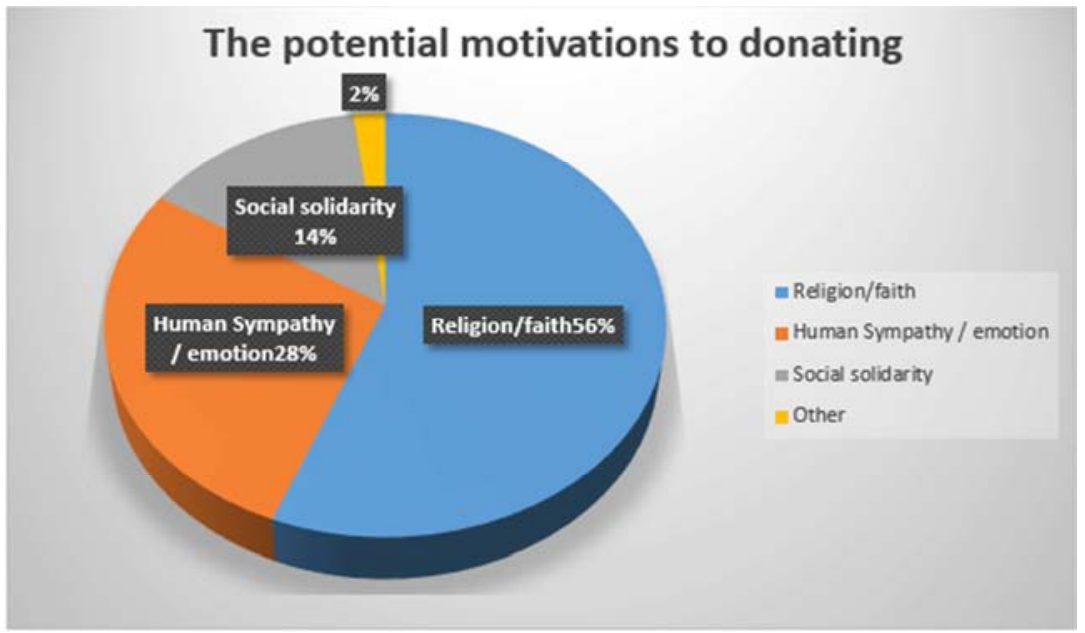

Figure 1. The potential motivations to donating / in general.

\subsection{The Three Potential Motivations to Donating / by Gender}

As shown in (figure 2), results showed that $69 \%$ of the males, who donated, donated from the religion / faith motive, while only $47 \%$ of the donating females donated from this motive. Thus, religiously-affiliated males donate to congregations or charitable organizations more than females. The percentage of females donating on the basis of human sympathy came out to be $38 \%$ compared to $12 \%$ from the males' side.

So, the human sympathy motive has a greater impact on the donating females than it does for males. Accordingly, the percentage difference between the two genders is significant. With respect to the concept of social solidarity, the results showed that $13 \%$ of the females were motivated by this concept, while males account for $15 \%$, thus, the percentage between males and females is so close when it comes to social solidarity. Other motivators such as but not limited to tradition and social prestige amount only to $2 \%$, where the ratio of male to female is negligible.

These findings conform to those of (Mesch, Brown, Moore \& Hayat, 2011), where the authors state that women score significantly higher than men on empathic concern. Also it conforms with Einolf (2011) that women have stronger prosocial values which are good predictors of charitable giving, in addition to (Einolf, 2009) as it was found that persons who describe themselves as caring and empathic are more likely to report making donations to charitable causes.

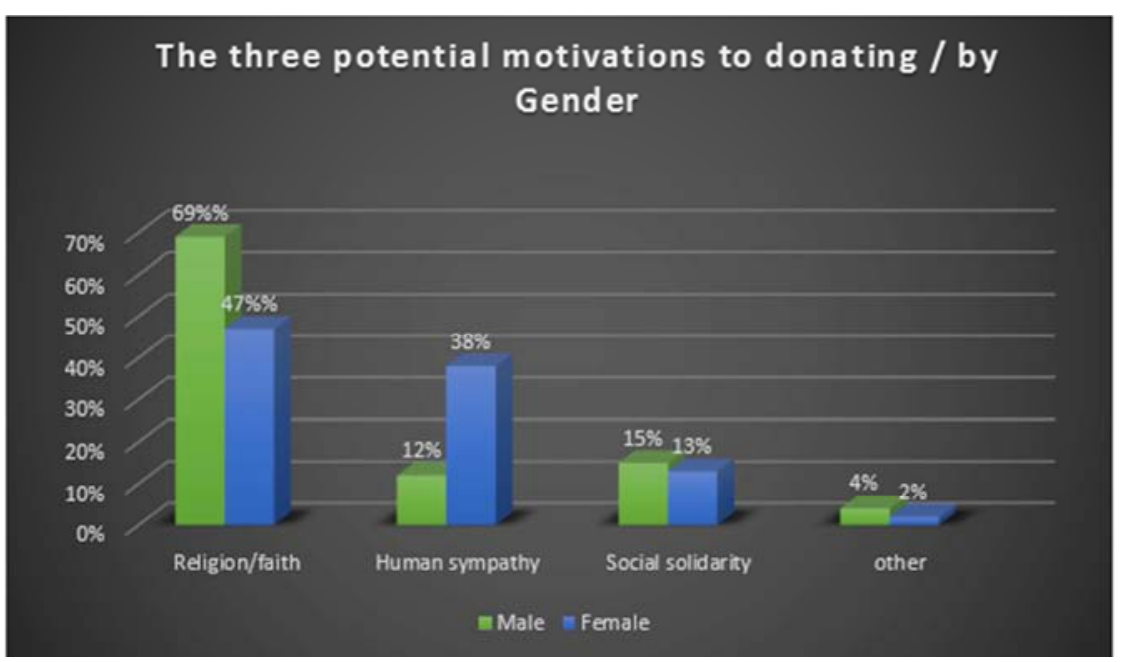

Figure 2. The three potential motivations to donating / by gender. 


\subsection{The Three Potential Motivations to Donating / by Education Level}

By analyzing the questionnaire the authors wanted to find out if there is a relation between donation and education level. As shown in (figure 3), the results came out as follows: $46 \%$ of those who answered religion / faith as their most important motive have a bachelor Degree, $49 \%$ are postgraduates and 4\% with different educational back ground. Human sympathy also plays various roles in motivating donors with different educational levels. For example, $55 \%$ of the respondents have a bachelor Degree, $40 \%$ have a Postgraduate, and only 5\% have different educational levels. With respect to social solidarity, $41 \%$ have a Bachelor Degree, and 56\% have a Postgraduate Degree are motivated by social solidarity, while only $3 \%$ have other degrees such as (secondary and intermediary education). So, people with a higher university degree tend to be moved more by social solidarity then those with intermediate and secondary degrees.

These findings conform to (The center of Philanthropy at Indiana University, 2009) where it was found that donors with postgraduate education stated that their main motivations are "making world better" and "for equity," and they are less concerned about "basic needs" or "poor help themselves."(social solidarity is number 1 in the findings), and with (Canadian Centre for Philanthropy, 2004) as they mentioned that donors with a university degree were significantly more likely than other donors to state that they gave because they felt that they owed something to their community" (Social solidarity is number 1 in the findings). Also conformity of findings appears in (Wiepking \& Bekkers, 2011) as the authors state that the higher educated is more supportive of social responsibility values than the lower educated.

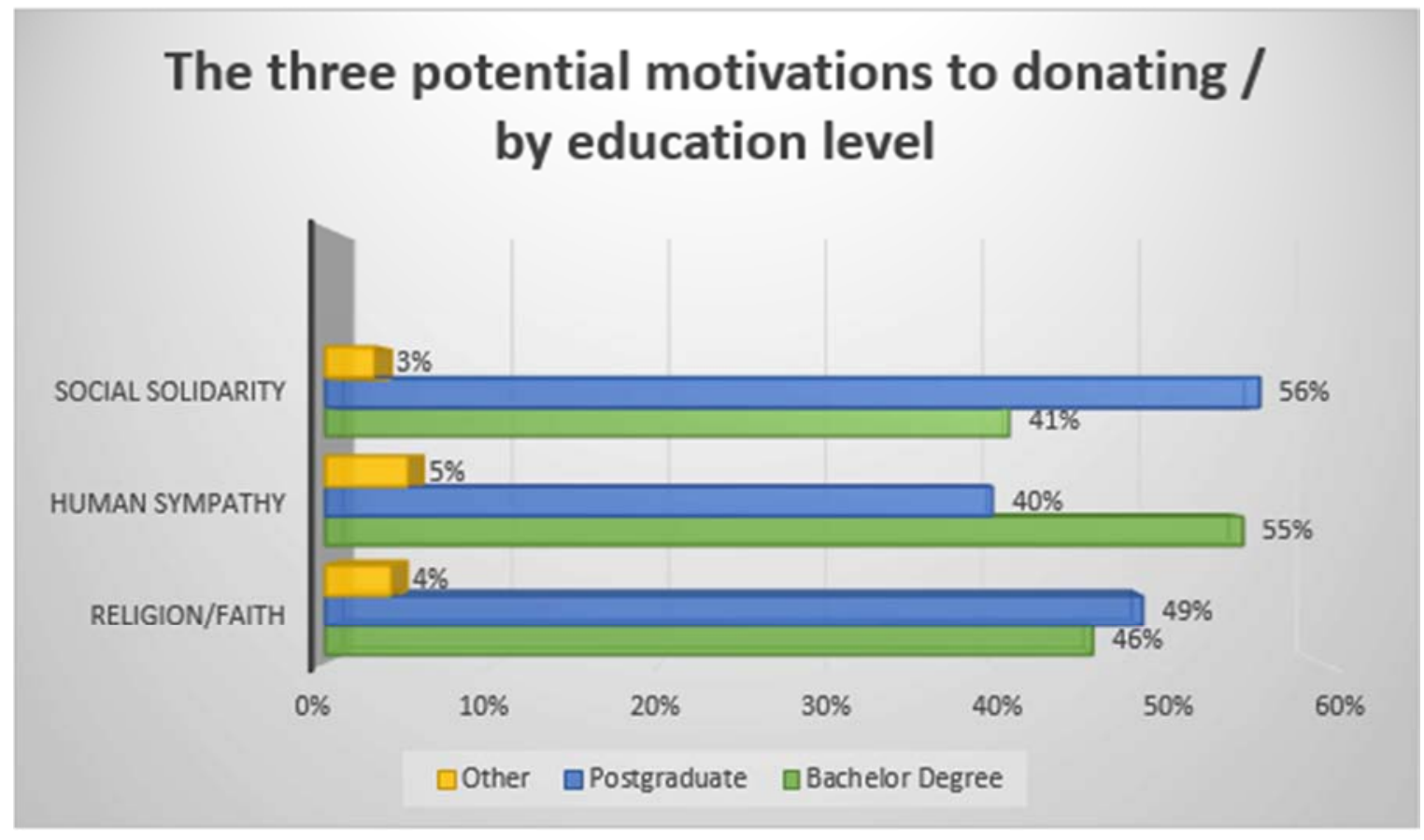

Figure 3. The three potential motivations to donating / by education level.

\subsection{Barriers to Donating}

This section analyzes the potential donors' barriers to donating and their relationship to gender, and educational level of donors.

\subsection{The Potential Barriers to Donating / in General}

As shown in (figure 4), the results came out as follows, Non-transparency amounted to $33 \%$, insistence in request for donation $21 \%$, and $23 \%$ for the lack of post donation reports. Organizational donor interaction 7\%,4\% delay in donation collection, financial errors $3 \%$, various $6 \%$, and only $3 \%$ were content with their organizations.

These findings conform to (Redbird on Canadian people, Murphy, L. (2001) as they found that 34\% said that they did not give more because they did not like how requests for donations were made. And when they were asked to say what exactly are the issues they didn't like in the requests, they said that the most frequent issue was the tone of the requests, then comes the frequency or volume of requests, and then receiving multiple requests from the same organization. Also conformity of the findings comes with the findings of (Barklays, 2010) where it appears that one of the barriers is: Charities' Efficiency: Concerns about the ways charities are run. Another one is (The Canadian Centre for Philanthropy, 2004) where their findings show that $47 \%$ of donors do not like how requests for donations were made, and $46 \%$ of donors thought that their donations would not be used efficiently. 


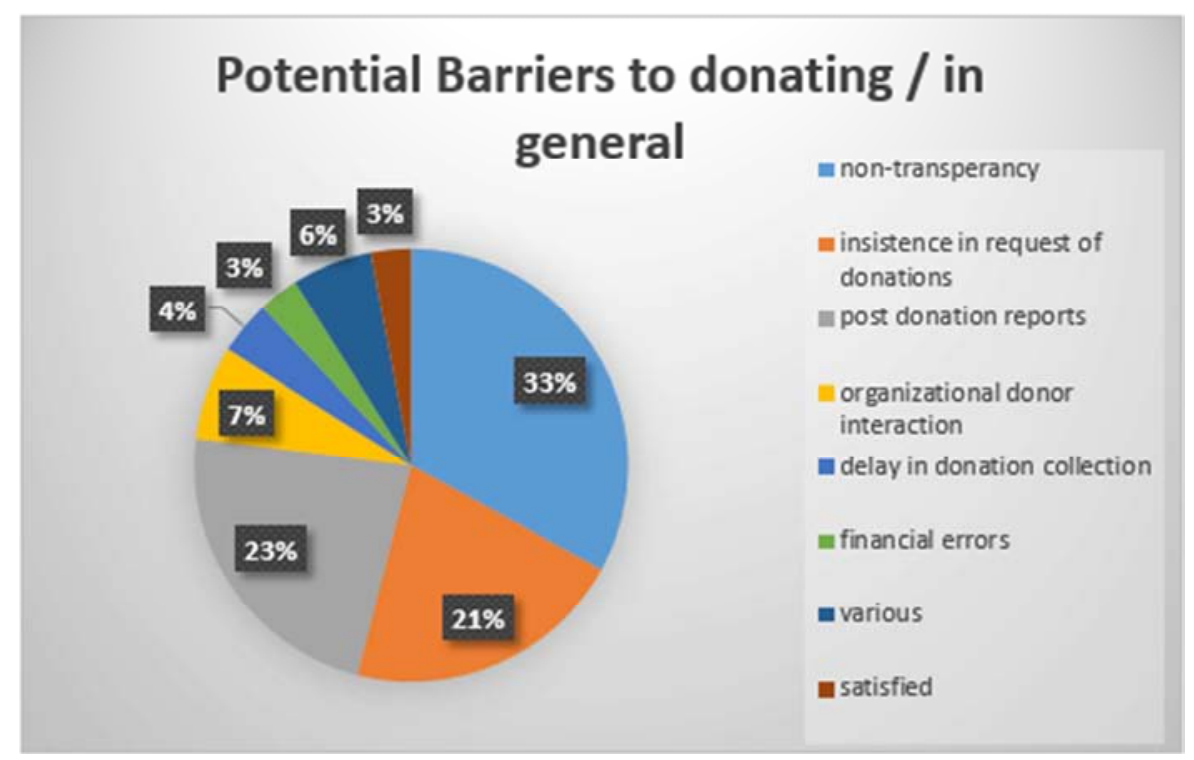

Figure 4. The potential barriers to donating / in general.

\subsection{The Potential Barriers to Donating / by Gender}

By trying to find the relation between organizational nontransparency and gender, the outcome came as follows, as shown in (figure 5): $29 \%$ of the males were bothered by organizational non-transparency compared to $36 \%$ of the females. As for the second in rank de-motivator, it is the lack of post donation reports, the gender percentages came out to be: only $19 \%$ of the females were bothered compared to $29 \%$ from the males' side. Thus, males were more bothered when it comes to the lack of post donation reports. With respect to insistence in request for donation, females seemed to be bothered more than males. Females amounted to $25 \%$, while the males' were about $15 \%$.

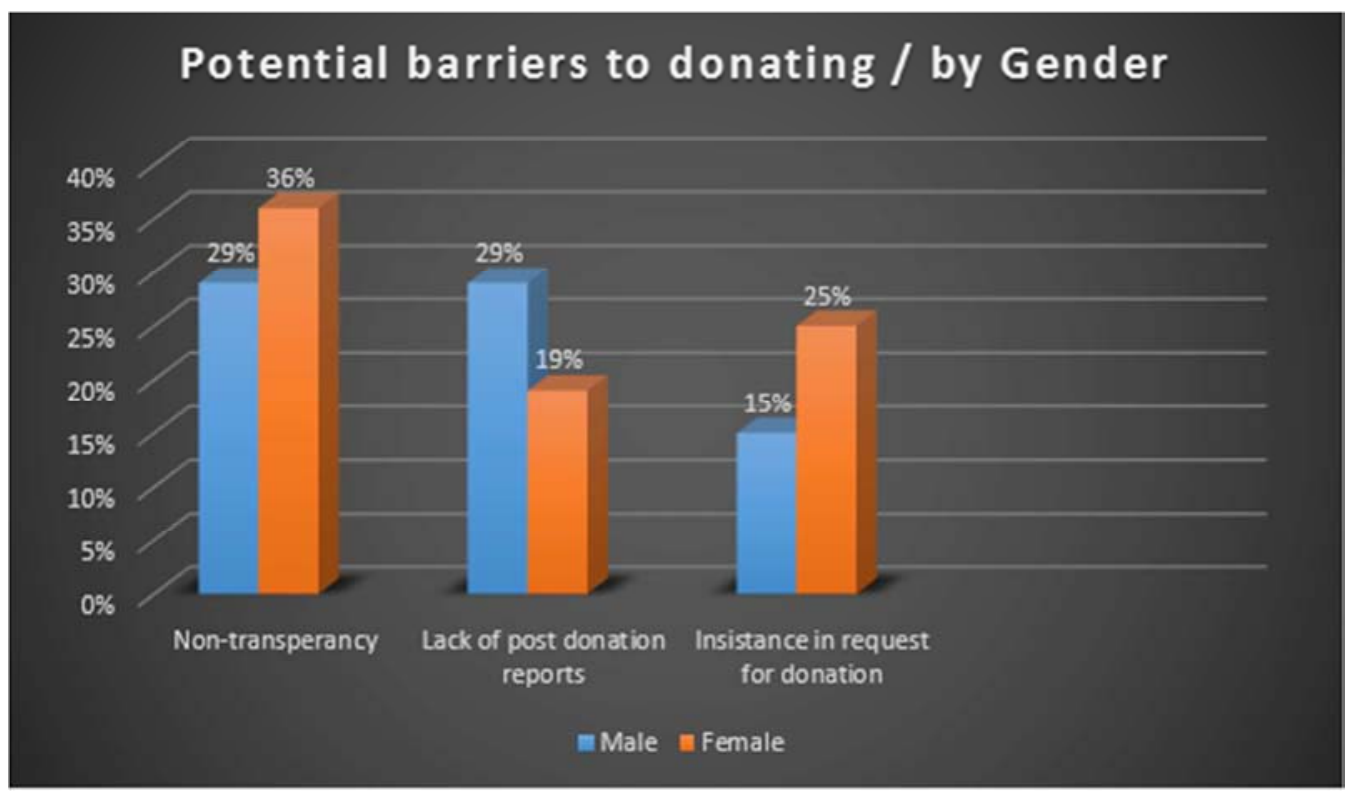

Figure 5. The potential barriers to donating / by gender.

\subsection{The Potential Barriers to Donating / by Education Level}

To check the impact of education level on the donor's discouraging factors, we had to interpret the results that came up as follows, as shown in (figure 6): Non-transparency disturbed $50 \%$ of those with a Bachelor degree, $48 \%$ with a postgraduate degree, and only $2 \%$ with different education levels. The lack of post donation reports had showed that $49 \%$ with a Bachelor degree, $47 \%$ postgraduate, and $4 \%$ with different education levels. As for the insistence in request of donations, $44 \%$ of those with a Bachelor degree are bothered, while $54 \%$ with a postgraduate degree, and only $2 \%$ with other educational level.

These findings conform with (Canadian Centre for 
Philanthropy, 2004) where it was mentioned that about one half donors with a post-secondary diploma or university degree said that they did not give more because they did not like the way in which requests are made (this conforms with: insistence in request of donations) .

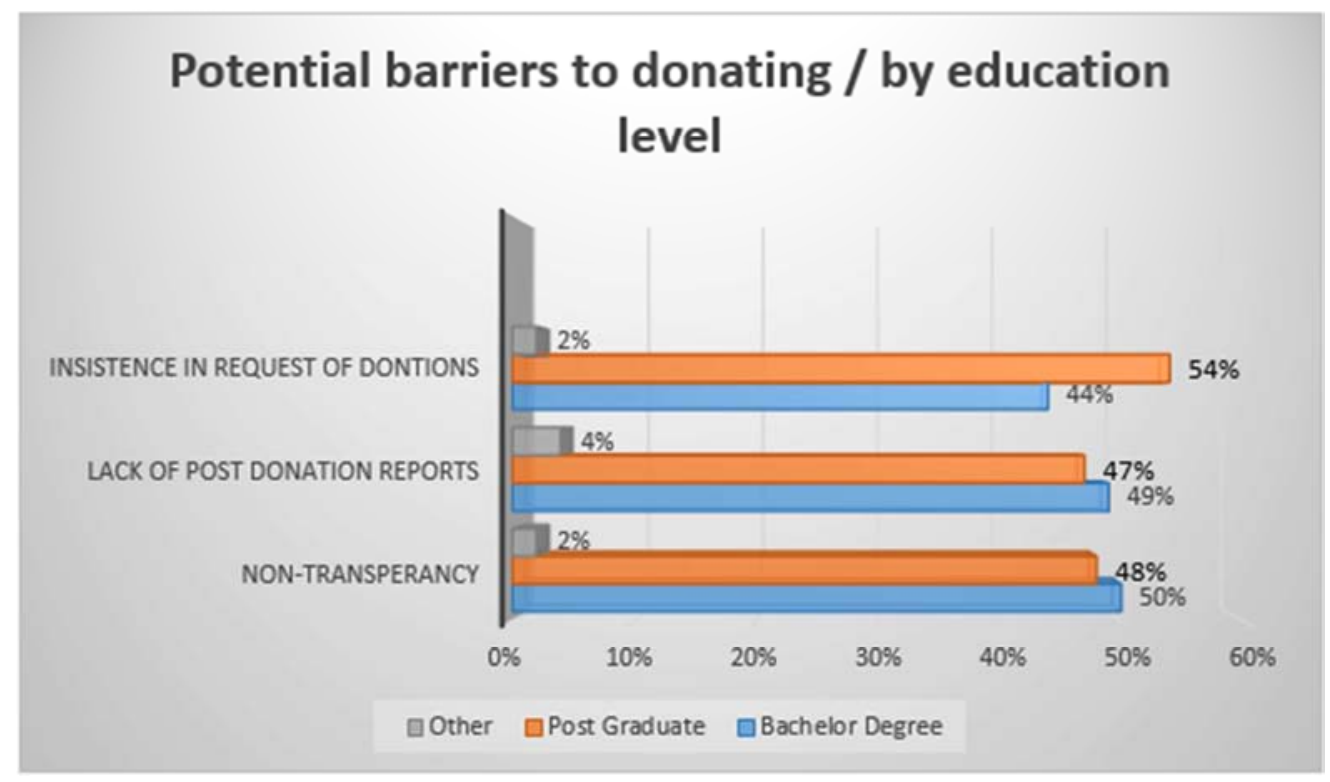

Figure 6. The potential barriers to donating / by education level.

\subsection{Motivation Factors in Choosing the Recipient NGO}

This section analyzes the potential donors' motivation factors in choosing the recipient NGO and their relationship with gender, and educational level of the donors.

\subsection{The Three Potential Motivation Factors in Choosing the Recipient $\mathrm{NGO}$ / in General}

As shown in (figure 7), the top three factors to choose an NGO, came out to be: Good reputation and trust amounting for a $49 \%$, importance of the cases requesting donation $36 \%$, belonging to the same religious affiliation $14 \%$, and $1 \%$ different factors.

These findings conform to (Adams and Cain, 2008) where the findings show that four factors affecting the donors' decision-making in choosing the recipient organization were recorded. These factors are: religious identity (conforms to same religious affiliation), effectiveness (conforms to Good reputation), being prior beneficiaries of the organization, and altruism (conforms to the importance of the cases requesting donations). Also we notice that the findings conform to the (Breeze, 2010) where it was stated that decision is based on many factors, one of which is "charity competence" (conforms with: good reputation).

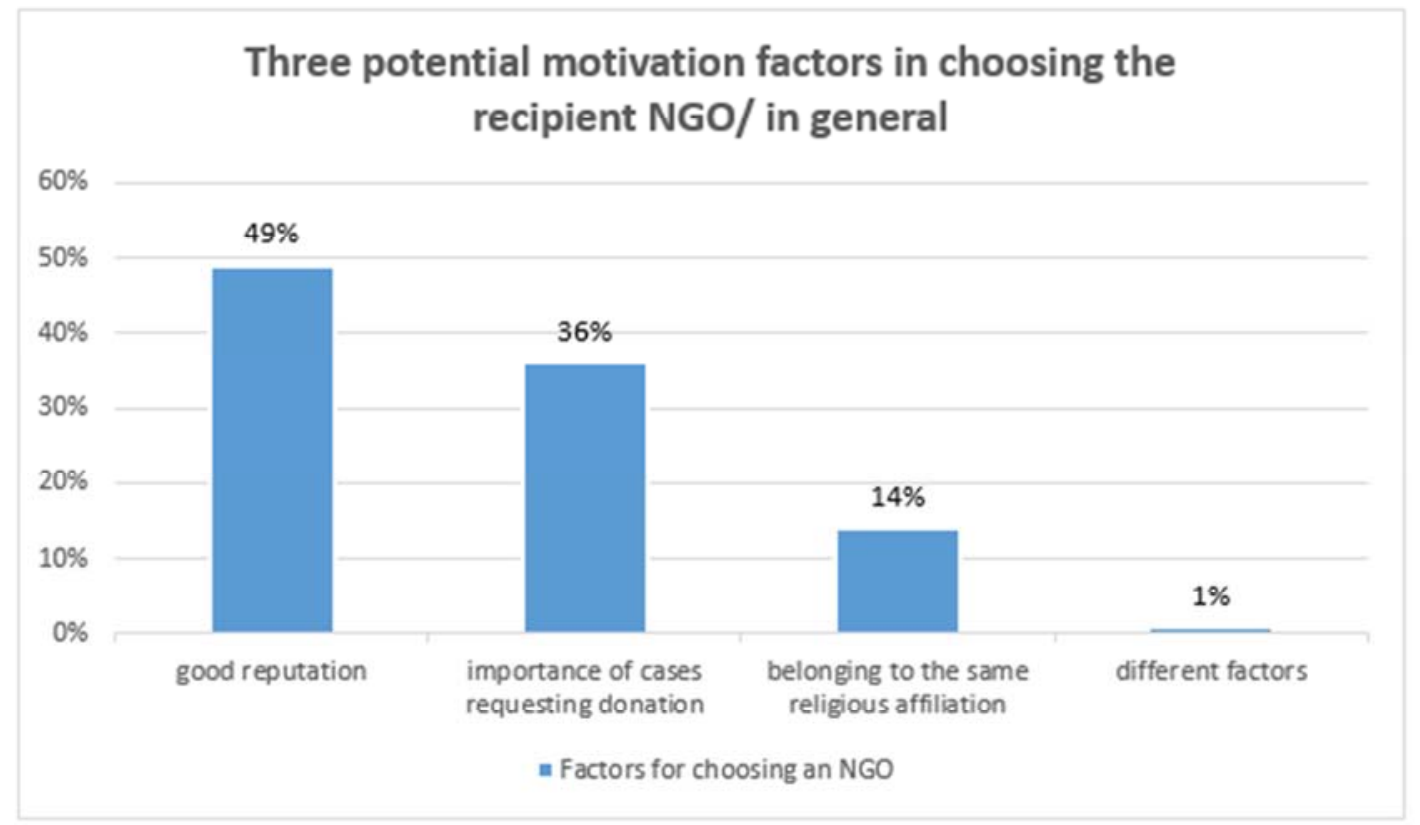

Figure 7. The three potential motivation factors in choosing the recipient $N G O /$ in general. 


\subsection{The Three Potential Motivation Factors in Choosing the Recipient NGO/ by Gender}

In order to find the relation between the effect of good reputation and its relation to gender, we analyzed the reports and came out with here below outcome, as shown in (figure $8)$.
Good reputation motivated $52 \%$ of the males and $47 \%$ of the females. On the other hand, importance of the cases requesting donation attracted $27 \%$ males and $42 \%$ females. While, belonging to the same religious affiliation results show that $33 \%$ of the males choose the NGO on this basis why only $2 \%$ of the females are motivated by this factor.

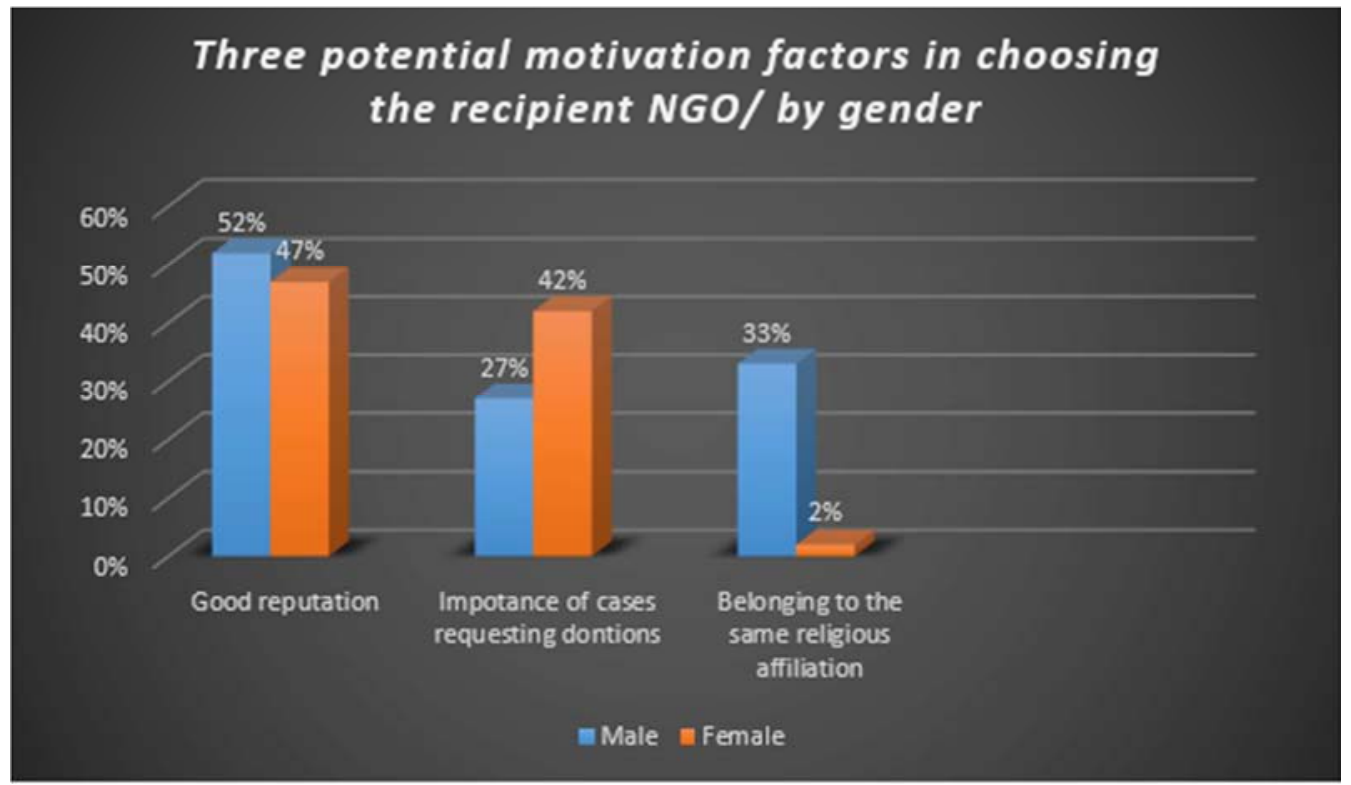

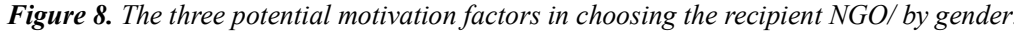

The Three Potential Motivation Factors in Choosing the Recipient $\mathrm{NGO} /$ by Education Level

The importance of education level in choosing a certain NGO according to its good reputation showed the following, as shown in (figure 9): $50 \%$ of those with a Bachelor Degree, $46 \%$ for postgraduate, and $4 \%$ of those with other education levels. With respect to the importance of the cases requesting donations the results showed, $43 \%$ of those with a Bachelor degree, $52 \%$ postgraduate, and $5 \%$ for other education levels. The motives for choosing an NGO basis the belonging to the same religious affiliation showed that, $53 \%$ for those with Bachelor degree, $44 \%$ for postgraduate, and 3\% for those with other education levels.

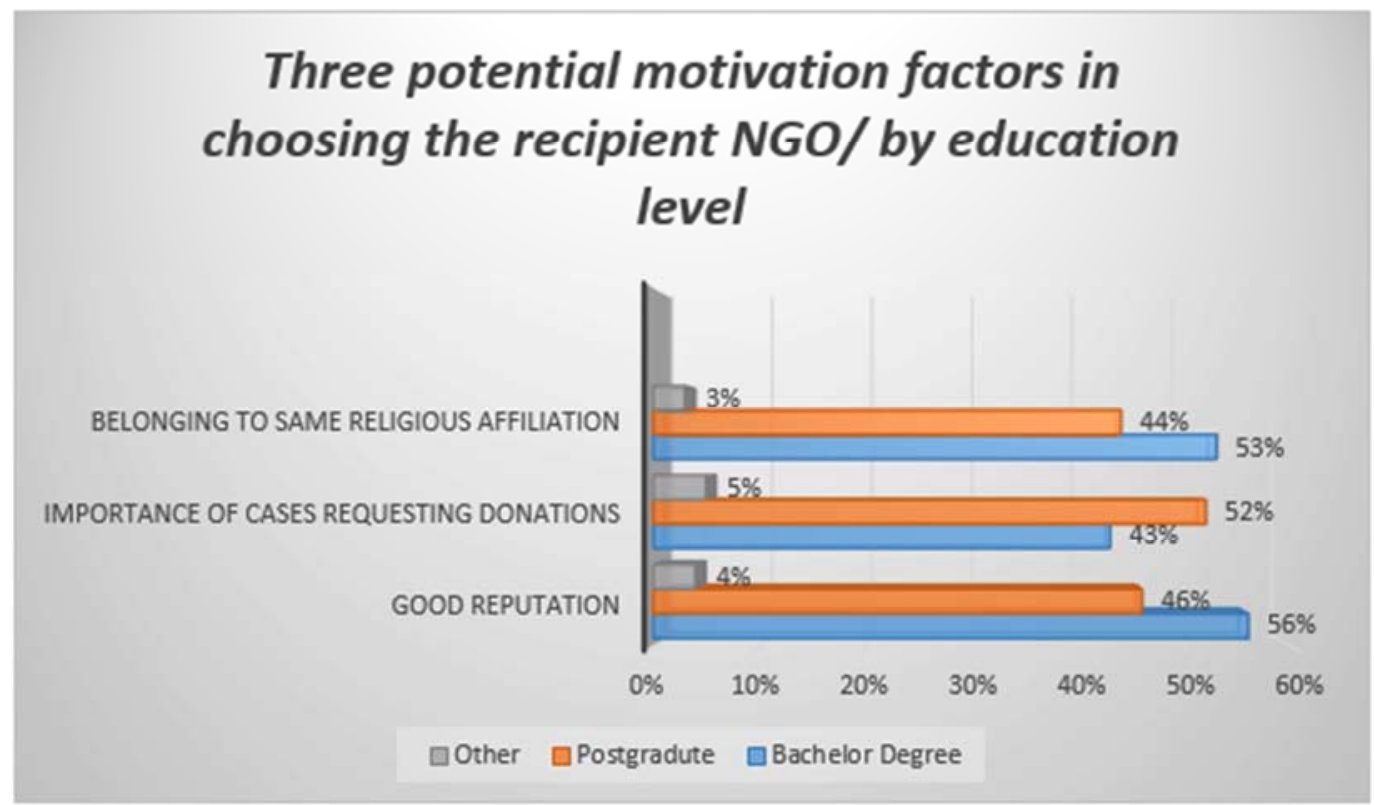

Figure 9. The three potential motivation factors in choosing the recipient NGO/ by education level. 


\section{Discussion}

Being a country where religion still has a great influence and a big significance not only on how the individuals think and behave but also on the society as a whole, Lebanon is driven by religious motives that shape the framework and determine human interpretation of reality combined with the background of their religious beliefs. The survey shows how deeply the seeds of human beliefs influence their attitude as well as behavior.

So, it is understandable why religion is the first motivation to donating, since Lebanon is a sectarian country where religion plays an important role in most aspects of life. Another reason is that most of the responses are from Muslim respondents, because the population of the Beirut area is from the Muslim religion, and as we know in Islam, donations are an obligatory commitment that comes in the form of zakat (alms) (2.5\% of wealth yearly), sadaqa (charity), or waqf (mortmain).

\section{Conclusion}

The motivation factors to donating vary in importance depending on gender and education level as follows: males are motivated by order of importance higher to lower: religion/faith, social solidarity, and human sympathy / emotion; while females are motivated by order of importance from higher to lower: religion/faith, human sympathy / emotion and social solidarity. As to the education role, bachelor degree donors top 3 motivating aspects by the order of their importance: Religion / faith, Human sympathy, Concept of social solidarity. Postgraduate donors top three motivating aspects by the order of their importance: Concept of social solidarity, Religion / faith, Human sympathy.

The de-motivation factors (or the barriers) to donate do vary according to gender and education as follows: Males are de-motivated by order of importance higher to lower: nontransparency and lack of post donation report fill the same rank, and then comes the insistence in the request of donations. Females are de-motivated by order of importance higher to lower: non-transparency, insistence in request of donations, and lack of post donation report. Thus, nontransparency is number 1 for both male and female donors. As to education role in de-motivating, bachelor degree donors top 3 de-motivating factors by the order of their importance: Non-transparency, Lack of post donation reports, and Insistence in request of donations. Postgraduate Degree donors top 3 de-motivating factors by the order of their importance: Insistence in request of donations, Nontransparency, Lack of post donation reports. Moreover, lack of post donation reports, and non-transparency fall approximately under the same rank with a negligible difference.

The factors affecting the decision of donors to choose the recipient NGO vary according to gender and education as follows: males are motivated by order of importance from higher to lower: Good reputation, same religious affiliation, and importance of the cases requesting donations. Females are motivated by order of importance from higher to lower: Good reputation, importance of the cases requesting donations, and belonging to the same religious affiliation. As to education, bachelor degree donors top 3 motivating factors to choose an NGO, by the order of their importance: belonging to the same religious affiliation, Good reputation, Importance of the cases requesting donations. Postgraduate Degree donors top three motivating factors to choose an NGO, by the order of their importance: Importance of the cases requesting donations, good reputation, belonging to the same religious affiliation. So, both gender and educational levels have an influence on choosing an NGO, and the variations between the educational levels are vivid.

\section{Limitations}

This paper analyzes only the monetary donations of individual practicing donors to charity institutions. It was conducted in the region of Beirut, the capital of Lebanon, and its near surroundings, where the majority are from the Islamic religion.

\section{Recommendations}

\section{Recommendations for Charities and NGOs}

This study explored the overall donors' motivations for giving without tackling specific circumstances. Based on the findings a list of recommendations is suggested to nonprofit organizations that seek to develop fundraising strategies, and implement tactical plans to attract more donors and retain current donors:

Although the percentage for donating on basis of religion/faith seems high we believe that NGOs' can't just rely on that factor alone. More should be done from their side to retain at least this percentage if not increase it, knowing that it remains the first important trigger to donate for both males and females. However, many factors intervene and intertwine.

While religion is the most motivational factor recorded, we believe that many religious people have the will to donate even after they have fulfilled their religious commitment. Here comes the role of fundraising strategists to compose the convenient message or call to donation in way that triggers the top two motivations after religions (human sympathy, and social solidarity). So, when the target donor is a female, it would be better to compose the donation request message from emotional elements that drives human sympathy, whereas when the target donor is a male, the best message would be the one that emphasizes the concept of human solidarity and the community and/or self-benefits that would be driven from this donation.

The higher the educational level, the more the individual tends to refer to the ties of society that binds people together. This tendency should be of concern to NGOs to work on 
sustainable development programs that satisfy the needs of this group of people and solicit funds from them. NGO's have to prepare themselves for the upcoming changes by:

Creating awareness to encourage donors to reflect on their assumptions.

Building solidarity by creating opportunities for dialogue and deliberation about how to address the issue at hand.

Enabling action by providing skills-based training.

Individual's perception of effectiveness and efficiency of their donations plays an important role on their future attitude towards this non-profit organization, especially among the highly-educated people. Therefore, NGOs should always take care of their post donation reports to their donors even if the donors don't ask for them. Donors nowadays have an increasing level of awareness, and NGOs are competing to attract those donors, so the more transparent you are the more credibility you offer to your donors.

Another recommendation for fundraisers is a careful study of the frequency and way of their requests. Insistence on requesting donations is one of the top three factors that bother the donor and may hinder the donor to donate more or to donate at all. In addition to this, the tone of the request should be very well designed by fundraisers who have to carefully select their approaches and messages to attract and convince donors.

Since the good reputation is the top factor that affects the decision making process of the donor to choose the recipient NGO, NGOs should work on the word of mouth marketing in their community, this is the best way to give a good reputation of the NGO and consequently to attract donors.

Also, fundraisers are recommended to do social researches about the causes that are really important to both the donor and the community in order to increase the probability of donations.

\section{References}

[1] Abou Assi K. (2015). Giving in Lebanon: Traditions and Reality in an Unstable Environment. In: Wiepking P., Handy F. (eds) The Palgrave Handbook of Global Philanthropy. Palgrave Macmillan, London

[2] Anheier, H. K., \& Salamon, L. M. (2006). The Nonprofit Sector in Comparative Perspective. In W. E. Powell \& R. Steinberg (Eds.), The Nonprofit Sector: A Research Handbook (Second Edition ed., pp. forthcoming). New Haven: Yale University Press

[3] B. Breeze. (2010). How donors choose charities. Centre for Charitable Giving and Philanthropy. University of Kent, London
[4] Barklays. (2010). Barriers to Giving. A white paper in cooperation with Ledbury Research

[5] Bekkers, R., \& Wiepking, P. (2010b). A literature review of empirical studies of philanthropy: Eight mechanisms that drive charitable giving. Nonprofit \& Voluntary Sector Quarterly, DOI: 10.1177/0899764010380927

[6] Byblos Bank, Economic Research \& Analysis Department. (2017). LEBANON THIS WEEK. Issue 514 | November 6-11, 2017

[7] Charities Aid Foundation. (2017). World Giving Index 107, A global view of giving trends.

https://www.cafonline.org/docs/default-source/about-uspublications/cafworldgivingindex2017_2167a_web_210917.p df? sfvrsn=ed 1 dac $40 \_10$

[8] Einolf, Christopher J. (2011). "Gender Differences in the Correlates of Volunteering and Charitable Giving." Nonprofit and Voluntary Sector Quarterly. 40:1092-1112

[9] J. Adams, B. Cain. (2008). Motivating Donors for Charitable Giving. Survey of Donors in Thurston County, Washington

[10] Kou X., Han H., and Frederick H. (2009). Gender Differences in Giving Motivations for Bequest Donors and Non-Donors. The Center on Philanthropy at Indiana University

[11] Mesch, D. J., Brown, M. S., Moore, Z. I. and Hayat, A. D. (2011). Gender differences in charitable giving. Int. J. Nonprofit Volunt. Sect. Mark., 16: 342-355. doi:10.1002/nvsm.432

[12] Murphy, L. (2001). Motivate and Convince: The Most Effective Tactics for Attracting Donors and Volunteers, Redbird

[13] Sharaiha, R, \& Ibrahim, B. L. (2009). The Republic of Lebanon. In B. L. Ibrahim \& D. Sherif (Eds.), Prom Charity to Social Change: Trends in Arab Philanthropy (pp. 111-131). Cairo, Egypt: American University in Cairo Press

[14] Srnka, K. J., Grohs, R., \& Eckler, I. (2003). Increasing Fundraising Efficacy by Segmenting Donors. Australasian Marketing Journal, 11(1), 70-86. Doi: https://doi.org/10.1016/S1441-3582(03)70119-0

[15] The center of Philanthropy at Indiana University. (2008). Generational Differences in Charitable Giving and in Motivations for Giving (A Report Prepared for Campbell \& Company). http://www.campbellcompany.com/news/generational-differencesin-giving

[16] Willer R., Wimer C., Owens L. A. (2015). What drives the gender gap in charitable giving? Lower empathy leads men to give less to poverty relief. Social Science Research, 52 (July 2015), 83-98. https://doi.org/10.1016/j.ssresearch.2014.12.014 